\title{
OPTIMIZING OF EXTRACTION OF BIOACTIVE COMPONENTS FROM SEA BUCKTHORN (HIPPOPHAE RHAMNOIDES L.) POMACE AND DEVELOPE OF ANTIOXIDANT-ENRICHED APPLE JUICE
}

\author{
${ }^{1}$ Diána Furulyás, ${ }^{1}$ Viktória Dobó, ${ }^{1}$ Dóra Székely, ${ }^{1}$ Rentsentdavaa Chaagnadorj, \\ ${ }^{2}$ Éva Stefanovits-Bányai, ${ }^{1}$ Mónika Stéger-Máté \\ ${ }^{1}$ Department of Food Preservation, Faculty of Food Science, Szent István University, Budapest, Hungary \\ ${ }^{2}$ Department of Applied Chemistry, Faculty of Food Science, Szent István University, Budapest, Hungary \\ e-mail: Furulyas.Diana@etk.szie.hu
}

\begin{abstract}
In our study, we were looking for an alternative to use of sea buckthorn pomace to open new opportunities. The dried pomace was extracted in a different method to achieve the highest antioxidant content. Ethanol and acetone were used as solvents, applied in different concentration. For the selection of the optimum extraction method, four spectrophotometric measurements were performed. With the best extract, three types of apple juice were made from apple juice concentrate by diluting it with different percentages of water and pomace extracts. The spectrophotometric measurements were also performed for juice samples to check the increase in amount of antioxidant components in the apple juice. Acceptability of enriched juices was determined by sensory evaluation and short market research. Based on the results the optimum extraction agent is $40 \mathrm{~m} / \mathrm{m} \%$ acetone for enriching apple juice. The results showed that there is a demand for the consumption of enriched juice with sea buckthorn pomace extracts and the fruit juice enriched with the 1:1 ratio of extract: water mixture is the most optimum according to sensory evaluators. Further examination could reveal whether the extracted antioxidant content of the pomace could be used as bio-preservatives in the food industry.
\end{abstract}

Keywords: sea buckthorn, pomace, apple juice, antioxidant, by-product, product-development

\section{INTRODUCTION}

The food waste is a critical subject in every industry, in every household; but in many cases by-products should not be considered as waste [1-3]. Fruit and vegetable wastes are produced in large quantities in food industry and constitute a source of nuisance in landfills because of their high biodegradability [4]. The nonedible portion of fruits and vegetables after processing (waste), such as peels, pods, seeds, skins, etc., accounts for about $10-60 \%$ of the total weight of the fresh produce. Because of the significant presence of pectin, minerals, vitamins, and bioactive molecules content, this waste offers a huge potential for its conversion into useful products, such as enzymes, ethanol, and biocolors [5]. The management of food processing by-products and wastes with reference to their reuse and recycling through value addition [6].

The European sea buckthorn (SB, Hippophae rhamnoides L.) is a deciduous shrub, which belongs to the Eleagnaceae family (Rosales). The berries of SB are rarely consumed fresh, but the fruit juice, pulp, and peel, and the seed oil are widely used in several countries. The SB is a good source of bioactive compounds as C-vitamin, carotenoid, flavonoid, polyphenolic content [7-9]. Processing of SB produces high amount of pomace, which are utilized rather inefficiently or discarded as a waste, so considerable amounts of nutrients are lost [10]. The pomace, which is left when berries are squeezed, is also a good source of vitamins and contains compounds that show antioxidant effects like flavonols, and phenolic acids are bioactive compounds. There is a growing interest in the utilization of antioxidant-rich plant extracts as dietary food supplements [11-12], so our goal is to find a method to extract this valuable antioxidant components and develop a delicious enriched apple juice with contain this pomace extracts. 


\section{MATERIALS AND METHODS}

The "Ascora" sea buckthorn was collected from agricultural plots of Hungary at 2017. For the measurements the all chemicals were purchased by Sigma-Aldrich Chemie Ltd. All reagents used were of analytical grade.

\subsection{Pre-treatment of sea buckthorn}

Sea buckthorn was destemmed and heated to $80^{\circ} \mathrm{C}$ to inactivate their enzymes. The berries were squeezed, resulting in juice and pomace (skin and seed). In the next step, the sea buckthorn pomace (SBP) was dried by atmospheric dryer (LMIM, Esztergom, Hungary) at $80^{\circ} \mathrm{C}$ until moisture content became lesser than 10 $(\mathrm{m} / \mathrm{m}) \%$. The moisture content was check by drying until constant weight at $121{ }^{\circ} \mathrm{C}$ using a MAC-50 moisture analyser (Radwag Waagen GMBH, Hilden, Germany). After that, the pomace was grinded. All SBP were stored in a freezer at $-20{ }^{\circ} \mathrm{C}$ until ready for extraction, which was performed at room temperature.

\subsection{Optimization of extraction condition}

Optimization of conditions for the extraction of antioxidants and phenolics components from dried SBP was determined using water, ethanol and acetone as solvents, applied in different concentration (in case of ethanol and acetone: $20(\mathrm{~m} / \mathrm{m}) \%$ and $40(\mathrm{~m} / \mathrm{m}) \%)$. The ratio between pomace and solvent was 1:30 proportions. After half-an-hour of extraction, the samples were placed into a supersonic bath for another 30 minutes (Bandelin Sonorex RK52), to intensify the process. The tube is centrifuged (SIGMA 204) at 5000 $1 / \mathrm{min}$ for $10 \mathrm{~min}$ to the phases separate and the supernatant is recovered. After the solvents were removed (by heating at $60^{\circ} \mathrm{C}$ ) and replaced with water, the evaporated and back diluted sample was treated with bentonite to give translucent, completely clear liquid.

\subsection{Measurements of antioxidant status of pomace extracts}

Various spectrophotometric measurements were carried out to select the highest antioxidant content of pomace extracts. All spectrophotometry measurements were performed in triplicate.

TPC: Total Polyphenol Content (TPC) was evaluated using a method by Singleton and Rossi [16]. The absorbance was measured at $765 \mathrm{~nm}$. Results were specified in $\mathrm{mg}$ gallic acid equivalent/ $100 \mathrm{~g}$ dried pomace (mg GA/100g).

- FRAP: The antioxidant capacity of samples was determined by Benzie and Strain [13]. This method is based on reduction of Fe3+, TPTZ (2,4,6-tripyridyl-s-triazine) complex to the ferrous Fe2+ form at low $\mathrm{pH}$. This reduction is followed by the measurement of absorption change at $593 \mathrm{~nm}$. Ferric reducing antioxidant power assay was defined in ascorbic acid equivalent ( $\mathrm{mg}$ ascorbic acid equivalent/ $100 \mathrm{~g}$ dried pomace; $\mathrm{mg}$ AA/100g).

- DPPH: The samples were measured in terms of hydrogen donating or radical scavenging ability using the stable radical DPPH (2,2-Diphenyl-1-picrylhydrazyl) [14]. The results were expressed as milligrams of Trolox equivalents (TE) per $100 \mathrm{~g}$ dried pomace (mg TE/100g). Higher absorbance of the reaction mixture indicates lower free radical scavenging activity.

- TEAC: The free radical-scavenging activity was estimated by ABTS radical cation decolorization assay according to the procedure described by Re et al. [15]. The results were corrected for dilution and expressed as milligrams of Trolox equivalents (TE) per 100 grams of dried pomace (mg TE/100g). 


\subsection{Processing of enrichment of apple juice}

With the best extraction method, three types of apple juice (11,2 $\mathrm{Brix}^{\circ}$, ATAGO PR-301) were made from apple concentrate $\left(70 \mathrm{Brix}^{\circ}\right)$ by diluting it to minimum $11,2 \mathrm{Brix}^{\circ}$ [according to Hungarian regulation of 152/2009] with different mixture of water and pomace extracts (Tab. 1.).

Table 1. Ingredients and name of juices

\begin{tabular}{|c|c|c|c|c|}
\hline \multicolumn{2}{|c|}{ Sample name } & Apple juice & Water & Pomace extract \\
\hline Control apple juice & CA & \multirow{3}{*}{70 Brix $^{\circ}$} & $100 \%$ & $0 \%$ \\
\cline { 1 - 1 } \cline { 4 - 5 } & & $50 \%$ & $50 \%$ \\
\hline $100 \%$ - enriched apple juice & EA1 & $0 \%$ & $100 \%$ \\
\hline
\end{tabular}

The spectrophotometry methods were carrying out also for the juices, the results expressed mg per litre juice $(\mathrm{mg} / \mathrm{L})$.

\subsection{Sensory evaluation of apple juice}

Acceptability of enriched juices was determined by sensory evaluation and short market research. The sensory evaluation was carried out with 30 lay judges, the samples were coded with three-digit numbers. The evaluation was based on 100-point system, during the analysis the attributes were as follows: colour (max. 20 point) turbidity (max. 10 point) flavoured (max. 10 point) taste (max. 40 point) sea buckthorn taste (max. 10 point) of juices and overall impression. Evaluations of the samples were carried out separately and independently without any influence.

\subsection{Statistical data evaluation}

Single-factor ANOVA was used for monitoring the relations of the results of the individual analytical methods on different extraction conditions, separately. Correlation analysis was used to analyse the relation of the results of the antioxidant measurements. The significance level of all tests was specified to be $\mathrm{P}=0.05$. The statistical evaluations were performed using Microsoft Excel.

\section{RESULTS AND DISCUSSION}

\subsection{Results of antioxidant measurements}

Dried SBP was extracted with different solvents (water, 20 and $40(\mathrm{~m} / \mathrm{m}) \%$ ethanol and acetone), the samples were analysed to define total polyphenol content, as well as their antioxidant capacity (FRAP, DPPH, TEAC), to find the most effective method of extraction to achieve an extract rich in biological activity components (Tab. 2.).

Table 2. The average results of the spectrophotometry measurements of the pomace extracts (mg/100g pomace)

\begin{tabular}{|l|c|c|c|c|c|}
\hline \multirow{2}{*}{ Water } & \multicolumn{2}{|c|}{ Acetone } & \multicolumn{2}{c|}{ Ethanol } \\
\cline { 3 - 6 } & & $\mathbf{2 0 \%}$ & $\mathbf{4 0 \%}$ & $\mathbf{2 0 \%}$ & $\mathbf{4 0 \%}$ \\
\hline TPC & $1026.26 \pm 100.23$ & $1587.54 \pm 164.61$ & $2265.99 \pm 598.66$ & $917.51 \pm 86.06$ & $1146.46 \pm 338.38$ \\
\hline FRAP & $324.11 \pm 114.65$ & $687.13 \pm 182.72$ & $1925.59 \pm 49.52$ & $486.47 \pm 403.95$ & $1295.21 \pm 197.13$ \\
\hline DPPH & $4464.29 \pm 4.46$ & $6422.99 \pm 6.42$ & $10796.13 \pm 10.79$ & $7047.99 \pm 7.05$ & $5630.58 \pm 5.63$ \\
\hline TEAC & $302.36 \pm 0.30$ & $687.86 \pm 0.68$ & $9708.45 \pm 9.71$ & $4931.78 \pm 4.93$ & $7276.74 \pm 7.28$ \\
\cline { 1 - 5 } & \multicolumn{3}{|c}{$x \pm S D(x:$ mean, SD: standard deviation }
\end{tabular}


Previous studies had also shown, that the fruits of SBT cultivars have strong antioxidant effect, and these results were right also in case of pomace extracts [17-19]. The results showed significant differences between the species $\left(\mathrm{p}_{\mathrm{TPC}}=2.5^{*} 10^{-3}, \mathrm{p}_{\mathrm{FRAP}}=2.8 * 10^{-5}, \mathrm{p}_{\mathrm{DPPH}}=7.4 * 10^{-14}, \mathrm{p}_{\mathrm{TEAC}}=6.3 * 10^{-19}\right.$ ). Based on the results the water as a solvent was not efficiently, these results of antioxidant measurements were the lowest value in most cases. The optimum extraction agent is acetone to the highest antioxidant content of pomace extracts. Between the extraction efficient of two concentration of acetone was significantly difference $(\mathrm{p}<0.05)$, so the best extraction solvent was the $40 \mathrm{~m} / \mathrm{m} \%$ acetone for extracting the valuable components from the pomace.

Table 3. The average results of the spectrophotometry measurements of the juice samples $(\mathrm{mg} / \mathrm{L})$

\begin{tabular}{|l|c|c|c|}
\hline & CA & EA1 & EA2 \\
\hline TPC & $372.80 \pm 11.57$ & $329.68 \pm 72.63$ & $462.15 \pm 19.79$ \\
\hline FRAP & $4338.54 \pm 477.06$ & $10494.78 \pm 1039.99$ & $14315.44 \pm 769.65$ \\
\hline DPPH & $150.67 \pm 2.01$ & $196.61 \pm 1.70$ & $398.56 \pm 1.87$ \\
\hline TEAC & $40.71 \pm 1.16$ & $197.04 \pm 0.70$ & $242.71 \pm 1.91$ \\
\hline \multicolumn{4}{|c|}{$x \pm S D(x:$ mean, SD: standard deviation }
\end{tabular}

Based on the results of juices (Tab 3.), our desired goal - the enrichment of apple juice - was met, the antioxidant compounds, the antioxidant capacity value of FRAP, DPPH and TEAC method greatly increased by added the pomace extract. The all measurements showed outstanding results compared to the control sample. The antioxidant content of the sample increases in direct proportions with the amount of added pomace extract. The sample EA2 (enriched apple juice, with $100 \%$ pomace extract) had the most antioxidant content.

Table 4. Results of correlation analysis between the antioxidant methods.

\begin{tabular}{|l|r|r|r|r|}
\hline & \multicolumn{1}{|l|}{ TPC } & \multicolumn{1}{l|}{ FRAP } & DPPH & TEAC \\
\hline TPC & 1 & & & \\
\hline FRAP & 0.79 & 1 & & \\
\hline DPPH & 0.84 & 0.78 & 1 & \\
\hline TEAC & 0.49 & 0.87 & 0.74 & 1 \\
\hline
\end{tabular}

This study assessed antioxidant potential of both extracts by using four different methods, which gave different antioxidant activity values (Tab. 2-3). From our values in Tab. 4, the greatest mutual correlation is shown between the results obtained by FRAP and TEAC methods, with the correlation coefficient being 0.87 . In case of the most methods the coefficient was greater than 0.74 , expect, the low correlation between TPC and TEAC was found. 


\subsection{Results of sensory analysis and market research}

The enriched apple juices had beneficial sensory properties (Fig.1), the tasters were satisfied with finished products.

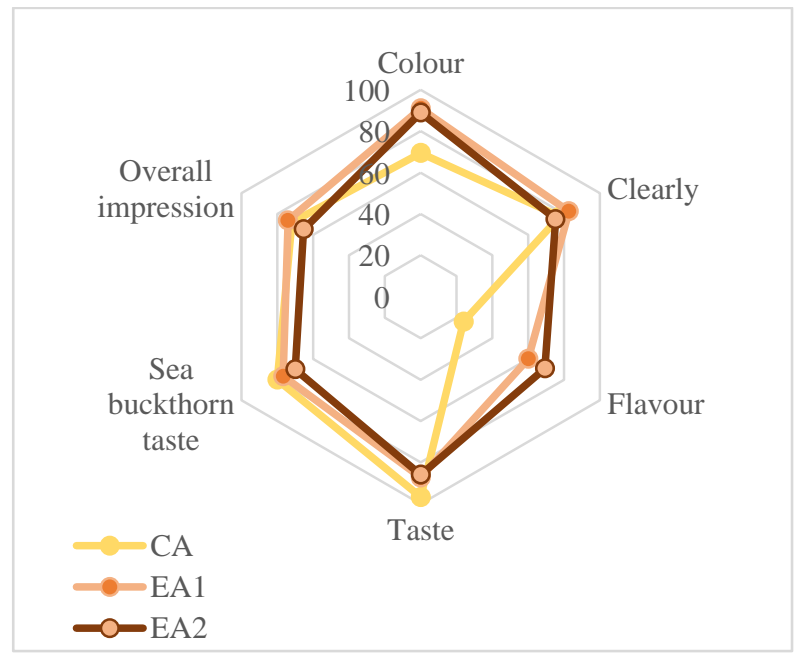

Figure 1. Results of sensory analysis

During product development, the flavour and sour flavour from SBP should be improved and decreased because the participants were the least satisfied with these parameters. According to the Fig. 2., apple concentrates dilute with $50 \%$ pomace extract (EA1 sample) is the most optimum according to evaluators. In case of this sample, the typical acidic flavour of the sea buckthorn did not yet negatively affect the taster and the ratio of apple and SBP was optimal and harmonic.

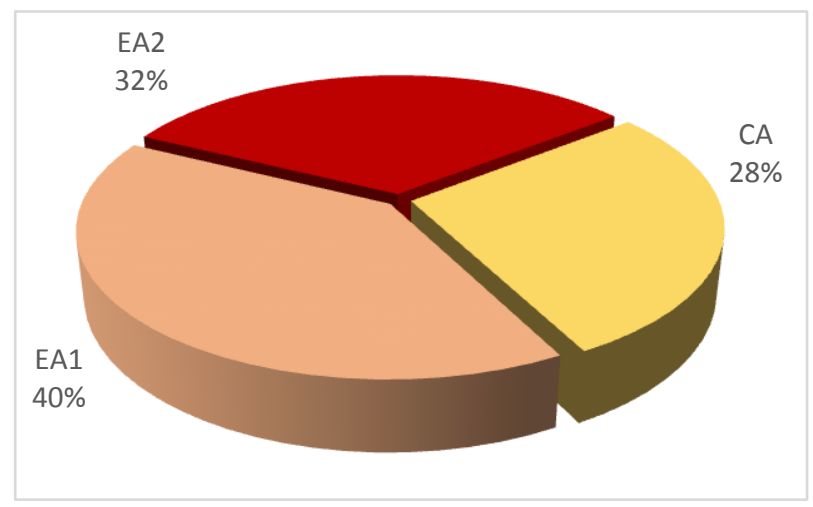

Figure 2. Results of market research, percentage distribution of popularity level

The results of the market research showed that there is a demand for the consumption of enriched juice. Overall, according to these data, consumers are open to new products, especially if they have a health benefit and are made up of natural materials. The $86 \%$ of tasters are happy to buy the finished products. It can be assumed that consumers have strong connect between the healthy diet and sea buckthorn, so the young and health conscious consumer can be targeted with this product. 


\section{CONCLUSIONS}

The aim of this research was to set up a technological process to obtain high-value biologically active extracts from sea buckthorn pomace, thereby helping to reduce waste from the juice industry. In the past few years, treating waste coming from the food industry, has become a remarkably important issue, due to environmental and economic reasons. Recycling waste should mean a satisfactory alternative, particularly, if we consider the amount of valuable components remaining in the waste of certain plants. On one hand, these could be retrieved using the proper method, and used again by the food industry. In our study, we have successfully recovered and recycled the antioxidant compounds from pomace of sea buckthorn to produce more valuable and special apple juice. These new aspects concerning the use of the pomace as byproducts for further exploitation on the production of food additives with high nutritional value, their recovery may decrease quantity of a waste of valuable components and may be economically attractive.

\section{ACKNOWLEDGEMENTS}

This work was supported by the Hungarian Government through project No. EFOP-3.6.3-VEKOP-162017-00005.

\section{REFERENCES}

[1] A. Mirzaei-Aghsaghali, N. Maheri-Sis, Nutritive value of some agro-industrial by-products for ruminants-A review. World J. Zool, 3 (2) (2008), pp. 40-46.

[2] K. Kónya, Élelmiszeripari hulladékok gyüjtése, ártalmatlanítása, hasznosítása. Szarvas, 5-6 (46) (2000), pp. 63-64

[3] S. Perino-Issartier, M. Abert-Vian, F. Chemat, Solvent free microwave-assisted extraction of antioxidants from sea buckthorn (Hippophae rhamnoides) food by-products. Food and Bioprocess Technology, 4 (6) (2011), pp. 1020-1028.

[4] S.N. Misi, C.F. Forster, Semi-continuous anaerobic co-digestion of agrowaste. Environ Technol 23 (2002), pp. 445-451.

[5] R. Sharma, H.S. Oberoi, G.S. Dhillon, Fruit and vegetable processing waste: renewable feed stocks for enzyme production. In Agro-Industrial Wastes as Feedstock for Enzyme Production (2016), pp. 23-59.

[6] J.G. Krishna, M. Chandrasekaran, Biochemical and nutritional aspects of food processing byproducts. Valorization of food processing by-products. (2012)

[7] Suryakumar G, and Gupta A. (2011). Medicinal and therapeutic potential of Sea buckthorn (Hippophae rhamnoides L.). J Ethnopharmacology 138, 268-278.

[8] E. Christaki, Hippophae rhamnoides L. (Sea Buckthorn): A Potential Source of Nutraceuticals. Food Public Health 2 (2012), pp. 69-72.

[9] J. Krejcarová, E. Straková, P. Suchý, K. Karásková, Sea buckthorn (Hippophae rhamnoides L.) as a potential source of nutraceutics and its therapeutic possibilities - A review. Acta Veterinaria Brno 84 (2015), pp. 257-268.

[10] C.M. Galanakis, Recovery of high added-value components from food wastes: conventional, emerging technologies and commercialized applications. Trends in Food Science \& Technology, 26 (2) (2012), pp. 68-87.

[11] C. Eccleston, Y. Baoru, R. Tahvonen, H. Kallio, G.H. Rimbach, A.M. Minihane, Effects of an antioxidant-rich juice (sea buckthorn) on risk factors for coronary heart disease in humans. The Journal of Nutritional Biochemistry, 13 (6) (2012), pp. 346-354.

[12] B. Yang, H.P. Kallio, Fatty acid composition of lipids in sea buckthorn (Hippophae rhamnoides L.) berries of different origins. Journal of agricultural and food chemistry, 49 (4) (2001), pp. 1939-1947. 
[13] V.L. Singleton, J.A. Rossi, Colorimetry of total phenolics with phosphomolybdic-phosphotungstic acid reagents. American journal of Enology and Viticulture, 16 (3) (1965) 144-158.

[14] I.I.F. Benzie, J.J. Strain, The ferric reducing ability of plasma (FRAP) as a measure of "antioxidant power": the FRAP assay. Analytical biochemistry, 239 (1) (1966) 70-76

[15] M.S. Blois, Antioxidant determinations by the use of a stable free radical. Nature, 181 (4617) (1958) 1199-1200.

[16] N.J. Miller, C. Rice-evans, M.J. Davies, V. Gopinathan, A. Milner, Factors influencing the antioxidant activity determined by the ABTS •+ radical cation assay. Free radical research, 26(3) (1993) 407-412.

[17] X. Gao, M. Ohlander, N. Jeppsson, L. Bjork, V. Trajkovski, Changes in antioxidant effects and their relationship to phytonutrients in fruits of sea buckthorn (Hippophae rhamnoides L.) during maturation. J Agric. Food Chem. 48 (2000) pp. 1485-1490.

[18] G. Korekar, P. Dolkar, H. Singh, R.B. Srivastava, T. Stobdan, Variability and the genotypic effect on antioxidant activity, total phenilics, carotenoids and ascorbic acid content in seventeen natural population of Seabuckthorn (Hippophae rhamnoides L.) from trans Himalaya. Food Science and Technology 55 (2014) pp. 157-162.

[19] R. Otakar, J. Turk, E. Sezai, M. Jiří, T. Juríková, I. Hoza, Antioxidant and radical cavenging activities in fruits of 6 sea buckthorn (Hippophae rhamnoides L.) cultivars. Turkish Journal of Agriculture and Forestry. 38(2) (2014), pp. 224232. 